\title{
Characteristics of Malaysian highly cited papers
}

\author{
A. Noorhidawati ${ }^{1}$, M.K. Yanti Idaya Aspura ${ }^{1}$, M.N. Zahila ${ }^{2}$ and A. Abrizah ${ }^{1,3}$ \\ ${ }^{1}$ Department of Library and Information Science, \\ Faculty of Computer Science and Information Technology, \\ University of Malaya, Kuala Lumpur, MALAYSIA \\ ${ }^{2}$ Library, International Islamic University of Malaysia, \\ Kuala Lumpur, MALAYSIA \\ ${ }^{3}$ Malaysian Citation Centre, \\ Ministry of Higher Education, Putrajaya, MALAYSIA \\ e-mail: noorhidawati@um.edu.my (corresponding author); yanti@um.edu.my; \\ zahila@iium.edu.my; abrizah@um.edu.my
}

\begin{abstract}
Highly cited papers serve as a proxy for excellence. In this paper, we identify Malaysia's highly-cited papers and explore the characteristics of these papers. The research question posed is "What characterizes Malaysian highly cited papers?" This study adopts the definition by Thomson Reuters Essential Science Indicator, i.e. the highly cited papers are papers that received enough citations to be placed in the top 1 percent of the academic field of each 22 subject areas based on a highly cited threshold for the field and publication year. As a small scientific nation, Malaysia has a rather limited number of papers being highly cited, and we observed nine characteristics of highly cited papers based on 708 datasets obtained from the Web of Science. Malaysian highly cited papers are largely represented by articles, but reviews have higher impact. Typically, these papers have a low self-cited index and they are published in the First Quartile of the science discipline publications. The papers are mainly the outcome of national funded research; involve multiple co-authorship and international collaboration; affiliated to Malaysian research universities and Malaysian authors often play a dominant role as first or reprint authors. Partnership with scientists from Iran, Australia and UK may increase markedly the possibility of a Malaysian paper becoming highly cited. This investigation has shown that these are the characteristics of Malaysian highly cited papers, but to what extent can these be used as indicators need further investigation and discussions among the scientific community.
\end{abstract}

Keywords: Highly cited papers; Citation analysis; Bibliometrics; Research evaluation; Research quality.

\section{INTRODUCTION}

The importance of scientific excellence has been widely documented in the existing scientometrics literature (Aksnes 2003; Aksnes and Sivertsen 2004; Fu et al. 2011; Miyairi and Chang 2012), but no standardized method of evaluating research influence has been universally accepted. It is generally agreed that scholars' influence on research can be measured by a common indicator, i.e. the number of citations they have (Aksnes 2003). However, when aggregated citation indicators are used to assess the scientific performance of a nation, the underlying citation distributions are seldom analysed (Aksnes and Sivertsen 2004. Citations are the references researchers append to their papers to explicitly show earlier works on which they have relied on to conduct their own investigations. As described in Eugene Garfield's reasons for citing a paper, the citations in scientific papers create a record of influence (Garfield 1955). Tracking citations and understanding their trends in 
context is a key to evaluating the impact of research. Not only can the influence of an individual research paper be traced through its citations in other papers, but the influence of a body of research in a specific domain can be determined. Ultimately, the scientific impact of a paper depends on the number of papers citing it, the scientific impact of the citing papers, and the role it plays in the citing papers (Fang 2015).

The more science policy focuses on research influence, the more researchers and institutions are confronted with evaluations based on citations. Using highly cited papers as indicators in research assessment has been an emerging interest since June 2014, when Thomson Reuters published a list of 3,215 highly cited researchers (available at http://highlycited.com/), based on the number of the top 1 percent most highly cited papers per author in the years 2002-2012. The percentile ranks were normalized using the 22 broad categories for journals in the Essential Science Indicator (ESI) as reference sets. Bornmann et al. (2013) indicated that the list has been appropriately used to identify excellent papers, because it indicates the ranks of papers in their categories as defined in ESI or the Web of Science (WoS).

Studies characterizing highly cited papers have become quite widespread in many disciplines and the need is arising as countries, funding agencies and universities are trying to gauge research performance and identify top researchers and research impact. To understand these characteristics, the common approach used is the bibliometric method. Most-cited papers with a significant influence, especially in medicine and health sciences, have been investigated in bibliometric literature (Baltussen and Kindler 2004; Paladugu et al. 2002; Ponce and Lozano 2010; Shadgan et al. 2010). Several studies on highly cited papers at the macro level (detailed in Table 1) highlight the general characteristics of these papers. These studies are based on the data in WoS and selected using the definition of highly cited set by ESI.

Aksnes's (2003) study of 297 Norway's highly cited papers identified typical characteristics such as they are authored by a large number of scientists and involve extensive international collaboration as quality dynamics. Similar studies conducted in China (Fu et al. 2011), Taiwan (Miyairi and Chang 2012) and Russia (Pislyakov and Shukshina 2014) substantiate the widely accepted view that international collaboration is almost a requirement for publishing highly cited papers. About 47 percent of all China ESI papers have collaboration with the group of eight (G8) highly industrialized nations, especially the United States (Fu et al. 2011). Taiwan's international collaboration in its production of highly cited papers remain relatively stable with USA with the highest number of collaboration, followed by China, Japan and Germany. However, Taiwan has increasingly collaborated with European countries whose output of highly cited papers is relatively high and increasing, rather than with its neighbouring countries in Asia (Miyairi and Chang 2012). Partnership with USA, German, UK, and French scientists increases markedly the probability of a Russian paper becoming highly cited. It is notable that although more than 90 percent of Russian highly cited papers involve international collaboration, Russian institutions often do not play a dominant role. (Pislyakov and Shukshina 2014). This shows that international and large number of co-authorship typically increases visibility of papers and proves to be profitable in terms of citations (Pislyakov and Shukshina 2014). Additionally, Chen, Arsenault, and Larivière (2015) reported the top 1 percent most cited papers exhibit higher levels of interdisciplinarity, implying that interdisciplinary research plays an important role in creating major scientific discoveries and generating high impact knowledge. 
Table 1: General Characteristic of Highly Cited Paper at the Macro Level

\begin{tabular}{|c|c|c|c|}
\hline No & Author & Country & General Characteristics \\
\hline 1 & Aksnes (2003) & Norway & $\begin{array}{l}\text { i. Highly cited papers are typically authored by a large } \\
\text { number of scientist } \\
\text { ii. Highly cited papers do typically involve international } \\
\text { collaboration } \\
\text { iii. Highly cited papers are mainly present in high impact } \\
\text { journal } \\
\text { iv. Review articles are over-represented among highly } \\
\text { cited papers } \\
\text { v. Highly cited papers are mainly cited by foreign } \\
\text { vi. The self-citations is very low for highly cited papers } \\
\end{array}$ \\
\hline 2. & $\begin{array}{l}\text { Pislyakov and } \\
\text { Shukshina (2014) }\end{array}$ & Russia & $\begin{array}{l}\text { i. Highly cited papers mainly involved international } \\
\text { collaboration } \\
\text { ii. Highly cited papers often have co-author(s) from at } \\
\text { least one foreign institution } \\
\text { iii. Highly cited papers resulted from bilateral } \\
\text { collaboration } \\
\text { iv. Highly cited papers distribution was dominated by } \\
\text { science field (physics) }\end{array}$ \\
\hline 3. & Fu et. al (2014) & China & $\begin{array}{ll}\text { i. } & \text { Highly cited papers were international collaboration } \\
\text { ii. Highly cited papers were published by many authors } \\
\text { iii. First and co-responding authors of highly cited papers } \\
\text { includes international authors } \\
\text { iv. Sciences (chemistry and physics) were the most } \\
\text { productive fields in the highly cited papers }\end{array}$ \\
\hline 4. & $\begin{array}{l}\text { Miyairi and } \\
\text { Chang (2016) }\end{array}$ & Taiwan & $\begin{array}{l}\text { i. Highly cited papers involve international } \\
\text { collaboration } \\
\text { ii. Highly cited papers distribution has strong } \\
\text { domination in science fields (engineering, clinical } \\
\text { medicine, physics) }\end{array}$ \\
\hline
\end{tabular}

Highly cited papers from the periphery world have received little attention in the literature. Malaysia's research excellence from the perspective of highly cited papers which represents "useful indicators for identifying world-class research" (Tijssen, Van Leeuwen and Visser 2002) is timely. Prior studies are restricted to Malaysia's overall scientific performance (Prathap and Ratnavelu 2015); performance in specific fields such as computer science (Bakri and Willett 2011), engineering (Tahira, Alias and Aryati 2015), medicine (Sanni et al. 2013) and health sciences (Zainal and Zainab 2011); performance of Malaysian journals (Abrizah et al. 2013); performance of Malaysian research reflected in Malaysia's WoS-indexed papers (Abrizah and Wee 2011; Ale Ebrahim et al. 2015), and Malaysia's international collaboration (Davarpanah 2009; Glänzel, Schubert and Czerwon 1999; Kumar and Jan 2013; Yu et al. 2013) or between Malaysia and particular countries (Alatas 2000; Arunachalam and Garg 1986; Kumar and Jan 2014; Nguyen and Pham 2001). In the case of Malaysia, acknowledging highly cited papers to denote research excellence is particularly appropriate, as it gives even more correct and interpretable results than the analysis of the entire national output. Malaysia's progress can be seen in the outstanding increase of scientific publications output between 2006 and 2016 and the production of papers that honour the 14 Malaysian researchers as the most influential in their respective fields, designated by Clarivate Analytics as highly cited papers (King 2016). However, it is not clear what one is measuring using highly cited papers 
and how this measure relates to world-class research. How different are highly cited papers from ordinary cited papers? It has been shown that highly cited papers are the results of international collaboration and multi-authorship (Aksnes 2003; Fu et al. 2011; Glänzel and Schubert 1995; Miyairi and Chang 2012; Persson 2010; Pislyakov and Shukshina 2014; Tijssen, Van Leeuwen and Visser 2002). Do these characteristics holfd true for Malaysian highly cited papers? To what extent do Malaysian authors dominate or are dominated in such a collaborative and multi-authorship works? Therefore, the objective of this investigation is to identify the characteristics of Malaysian highly cited papers. The research question posed is "What characterizes Malaysian highly cited papers?" It should be noted that the objective and research question of the study are exploratory and descriptive in nature. Identification of these characteristics may play a key role in determining highly cited Malaysian papers.

\section{MATERIALS AND METHOD}

The bibliometric studies reviewed earlier (Table 1) have shown a uniform pattern for highly cited papers. Although the term highly cited paper may be defined in a number of ways (Aksnes 2003; Aksnes and Sivertsen 2004; Garfield 1955) this study adopts the definition given by ESI, i.e. the highly cited papers are papers that received enough citations to be placed in the top 1 percent of the academic field of each 22 subject areas based on a highly cited threshold for the field and publication year. This is justifiable since the data were collected from WoS Core Collection database. "Malaysia" was used as a keyword for address search and the search was refined using highly cited papers indicated in ESI. Highly cited articles dated from 2006-2016 were identified. A 10-year interval was determined because this is the cumulative time period used for ESI to calculate the highly cited papers. This study has included all 22 subject areas from three types of scientific papers, namely article, review and proceeding, and excluded the rest of the paper type. As a result, 708 papers comprising 443 articles, 258 reviews and 7 proceedings, along with the total citation count of 70660 , was automatically extracted from WoS into a CSV file. These data were analysed to descriptively report and characterize the Malaysian highly cited papers. Table 2 presents the number of papers and citations based on the year of publication, thus indicating the growth in the number of highly cited papers since 2006.

Table 2: Malaysian Highly Cited Papers and the Citation Impact based on the Year of Publication

\begin{tabular}{c|c||c|c}
\hline \hline Year of Publication & No of Paper & Percentage of Paper & No of Citation \\
\hline 2006 & 12 & 1.7 & 3312 \\
\hline 2007 & 17 & 2.4 & 4701 \\
\hline 2008 & 27 & 3.8 & 6288 \\
\hline 2009 & 42 & 5.9 & 8655 \\
\hline 2010 & 50 & 7.1 & 9073 \\
\hline 2011 & 68 & 9.6 & 11601 \\
\hline 2012 & 73 & 10.3 & 7118 \\
\hline \hline 2013 & 89 & 12.6 & 7321 \\
\hline \hline 2014 & 126 & 17.8 & 7188 \\
\hline \hline 2015 & 144 & 20.3 & 4872 \\
\hline \hline 2016 & 60 & 8.5 & 531 \\
\hline \hline Total & $\mathbf{7 0 8}$ & $\mathbf{1 0 0 . 0}$ & $\mathbf{7 0 6 6 0}$ \\
\hline \hline
\end{tabular}




\section{RESULTS AND DISCUSSIONS}

The following results report and discuss the characteristics of Malaysian highly cited papers in WoS. We have observed 9 characteristics, similar to Aksnes (2003), that influences the direction of this study. The style of analysis is exploratory and findings are presented in themes.

\section{a) Malaysian highly cited papers are more represented by articles, but reviews have more impact}

It has been shown that review papers are over-represented among highly cited papers (Aksnes 2003). This characteristic was not found in the current study. Instead Malaysian highly cited papers are mainly represented by articles ( 62.6 percent). From the 708 papers, 443 are research articles, 258 reviews and 7 proceedings with citations of 38342,32318 , and 845 garnered respectively (Table 3 ). However, review papers received higher citation impact with an average citation of 125.22 per paper, compared to articles with an average of 86.55 citations per paper.

\section{b) Malaysian highly cited papers are lowly self-cited}

Findings indicate that Malaysian highly cited papers are lowly self-cited with the total times cited with self-citations at 610 ( 0.9 percent), and the total times cited without self-citations at 70895 (99.1 percent). Details are presented in Table 3. Author self-citations account for a relatively large share of all self-citations and studies have shown that poorly cited papers have the highest self-citation share (Aksnes 2003; Davarpanah and Farzaneh 2009). In the case of highly cited papers, the share of self-citation is very low because high citation counts cannot be easily obtained from self-citations and self-citation rates are also taken into consideration as a factor in the journal evaluation process of Web of Science Core Collection citation index (Garfield 1990; Testa 2016).

Table 3: Citation Count of Highly Cited Papers $(n=708)$

\begin{tabular}{l||r|r||r||r}
\hline \hline Type of Papers & $\begin{array}{c}\text { No of Papers } \\
\text { (Percentage) }\end{array}$ & Times Cited & $\begin{array}{c}\text { Times Cited without } \\
\text { Self-citations }\end{array}$ & $\begin{array}{c}\text { Average Citations } \\
\text { Per Paper }\end{array}$ \\
\hline \hline Article & $443(62.6)$ & 38342 & 37963 & 86.55 \\
\hline \hline Review & $258(36.4)$ & 32318 & 32088 & 125.26 \\
\hline \hline Proceeding & $7(1.0)$ & 845 & 844 & 120.71 \\
\hline \hline Total & $\mathbf{7 0 8 ( 1 0 0 . 0 )}$ & $\mathbf{7 1 5 0 5}$ & $\mathbf{7 0 8 9 5}$ & $\mathbf{3 3 1 . 5 1}$ \\
\hline \hline
\end{tabular}

\section{c) Malaysian highly cited papers are mainly published in the First Quartile}

Based on the findings, it has been descriptively demonstrated that scientific papers that are most cited tends to be published in high impact journals denoted by their impact factor. Because impact factor is incomparable across different research disciplines, Fieldnormalized Journal Impact Factor (JIF) has been used (Leydesdorff and Bornmann 2011; Moed 2010), and the JIF Quartile is the commonly used one to evaluate an entity's (e.g., a country's, institution's, research group's or individual's) publications distribution among journals of different fields. To analyse what is the real proportion of Malaysian highly cited papers allocated in the top journals, we identified the JIF Quartile of the 708 papers from the Journal Citation Report (JCR). As can be seen from Table 4, a very high percentage of Malaysian highly cited papers (79 percent) appear in journals that are ranked in the first 
quartile. In contrast, a very low percentage (less than 1 percent) appears in the category of journals cited below average (Quartile 4). Our analysis shows that Malaysian highly cited papers are predominantly published in high impact journals. However, other studies have reported that in order to be highly cited, it is not necessary to be published in high impact journals (Aksnes 2003; Martín-Martín et al. 2016; Meho and Yang 2007).

Table 4: Quartile Journal Ranking of Highly Cited Papers

\begin{tabular}{c||r||r||r||r}
\hline \hline Journal Quartile & No of Papers & Percentage & No of Citations & \multicolumn{2}{c}{ Citation Percentage } \\
\hline \hline Quartile 1 (Q1) & 559 & 79.0 & 60070 & 85.0 \\
\hline \hline Quartile 2 (Q2) & 111 & 15.7 & 8559 & 12.1 \\
\hline \hline Quartile 3 (Q3) & 26 & 3.7 & 1047 & 1.5 \\
\hline \hline Quartile 4 (Q4) & 5 & 0.7 & 701 & 1.0 \\
\hline \hline NA & 7 & 1.0 & 283 & 0.4 \\
\hline \hline Total & $\mathbf{7 0 8}$ & $\mathbf{1 0 0}$ & $\mathbf{7 0 6 6 0}$ & $\mathbf{1 0 0}$ \\
\hline \hline
\end{tabular}

\section{d) Malaysian highly cited papers are from the sciences}

The subject of a paper to be cited has been argued to be an important factor in explaining frequent citations. However, knowledge on this issue appears to be limited. We are interested to know to what extent a particular subject field characterizes Malaysian highly cited papers. The 708 highly cited papers were categorized according to 184 WoS categories, which we re-categorized into five broad subjects based on the Malaysian Citation Centre (MCC) (http://www.myjurnal.my/public/about.php) classification (as shown in Table 5). Our analysis shows that Malaysian highly cited papers are predominantly from the Sciences (98.7 percent, 420 papers) and only one percent (9 papers) from the Social Sciences. Engineering \& Technology has the highest contribution to Malaysian highly cited papers, followed by Science, and Medical \& Health Sciences. Table 6 details the top 20 specific subject categories in which Malaysian research is highly cited. The highest category is Green and Sustainable Science and Technology; Energy and Fuels, with a total of 14.4 percent (102 papers), followed by Medicine, General and Internal, and Engineering, Environmental; Engineering, Civil; Environmental Sciences, with 4.7 percent (33 papers) respectively. This shows that Malaysian highly cited papers do not exhibit a high level of interdisciplinarity, thus implying a low level of interdisciplinary research.

Table 5: Broad Subjects and No of Papers

\begin{tabular}{l||r|r}
\hline \hline Subjects & No of Papers & Percentage \\
\hline \hline Engineering \& Technology & 368 & 52.0 \\
\hline \hline Science & 216 & 30.5 \\
\hline \hline Medical \& Health Sciences & 115 & 16.2 \\
\hline \hline Social Sciences & 9 & 1.3 \\
\hline \hline Arts \& Humanities & 0 & 0.0 \\
\hline \hline Total & $\mathbf{7 0 8}$ & $\mathbf{1 0 0 . 0}$ \\
\hline \hline
\end{tabular}


Table 6: Top 20 Subject Category of Highly Cited Papers

\begin{tabular}{|c|c|c|c|c|}
\hline No & Specific Subject Category (WOS) & Broad Subject (MCC) & No of Papers & Citation \\
\hline 1 & $\begin{array}{l}\text { Green and Sustainable Science and Technology; } \\
\text { Energy and Fuels }\end{array}$ & $\begin{array}{l}\text { Engineering and } \\
\text { Technology }\end{array}$ & 102 & 8271 \\
\hline 2 & Medicine, General and Internal & $\begin{array}{l}\text { Medical and Health } \\
\text { Sciences }\end{array}$ & 33 & 6769 \\
\hline 3 & $\begin{array}{l}\text { Engineering, Environmental; Engineering, Civil; } \\
\text { Environmental Sciences }\end{array}$ & $\begin{array}{l}\text { Engineering and } \\
\text { Technology }\end{array}$ & 33 & 5702 \\
\hline 4 & $\begin{array}{l}\text { Thermodynamics; Energy and Fuels; Mechanics; } \\
\text { Physics, Nuclear }\end{array}$ & $\begin{array}{l}\text { Engineering and } \\
\text { Technology }\end{array}$ & 29 & 1117 \\
\hline 5 & $\begin{array}{l}\text { Engineering, Environmental; Engineering, } \\
\text { Chemical }\end{array}$ & $\begin{array}{l}\text { Engineering and } \\
\text { Technology }\end{array}$ & 28 & 3412 \\
\hline 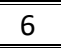 & Physics, Particles and Fields & Sciences & 21 & 1013 \\
\hline 7 & Multidisciplinary Sciences & Sciences & 17 & 1925 \\
\hline 8 & Thermodynamics; Energy and Fuels & $\begin{array}{l}\text { Engineering and } \\
\text { Technology }\end{array}$ & 15 & 1162 \\
\hline 9 & $\begin{array}{l}\text { Chemistry, Physical; Electrochemistry; Energy and } \\
\text { Fuels }\end{array}$ & Sciences & 12 & 1332 \\
\hline 10 & Genetics and Heredity & $\begin{array}{l}\text { Medical and Health } \\
\text { Sciences }\end{array}$ & 12 & 904 \\
\hline 11 & Energy and Fuels; Engineering, Chemical & $\begin{array}{l}\text { Engineering and } \\
\text { Technology }\end{array}$ & 12 & 821 \\
\hline 12 & $\begin{array}{l}\text { Green and Sustainable Science and Technology; } \\
\text { Engineering, Environmental; Environmental } \\
\text { Sciences }\end{array}$ & $\begin{array}{l}\text { Engineering and } \\
\text { Technology }\end{array}$ & 12 & 511 \\
\hline 13 & $\begin{array}{l}\text { Astronomy and Astrophysics; Physics, Nuclear; } \\
\text { Physics, Particles and Fields }\end{array}$ & Sciences & 12 & 454 \\
\hline 14 & $\begin{array}{l}\text { Chemistry, Applied; Food Science and Technology; } \\
\text { Nutrition and Dietetics }\end{array}$ & Sciences & 11 & 1603 \\
\hline 15 & Engineering, Chemical; Water Resources & $\begin{array}{l}\text { Engineering and } \\
\text { Technology }\end{array}$ & 11 & 1169 \\
\hline 16 & Food Science and Technology & $\begin{array}{l}\text { Medical and Health } \\
\text { Sciences }\end{array}$ & 11 & 585 \\
\hline 17 & $\begin{array}{l}\text { Astronomy and Astrophysics; Physics, Particles and } \\
\text { Fields }\end{array}$ & Sciences & 9 & 421 \\
\hline 18 & Gastroenterology and Hepatology & Sciences & 8 & 1309 \\
\hline 19 & Mathematics, Applied & Sciences & 7 & 455 \\
\hline 20 & $\begin{array}{l}\text { Chemistry, Applied; Chemistry, Organic; Polymer } \\
\text { Science }\end{array}$ & Sciences & 6 & 932 \\
\hline
\end{tabular}

\section{e) Malaysian highly cited papers are outcomes of national funded research}

Funding has been viewed in the literature as one of the determinants of research activities. Funding agencies do not only focus on how the money is spent, but also on the impact of new and important discoveries in improving life. The research community suggests that a highly cited paper is an outcome of funded research (Patsopoulos 2006; Paul-Hus, Desrochers and Costas 2016).

Information about funding was obtained from the acknowledgement section of each paper. From Table 6 we can conclude that most of the highly cited papers are outcomes of funded research with a total of 435 papers (61.4 percent), of which 35 percent (248 papers) acknowledged more than one funder and 26.4 percent (187 papers) indicated a single funder. About 38.6 percent (273 papers) did not acknowledge any specific grant 
from any funding agency. Table 7 also shows that the majority of the highly cited papers are in fact outcomes of national funded research (62.1 percent). A total of 164 papers acknowledged both the Ministry of Higher Education (MOHE) Malaysia and University of Malaya (UM) as the funding agencies, and these papers are mainly in Engineering \& Technology, with a total citation of 3277, of which 89 papers are outcome of the High Impact Research (HIR) grant funded by MOHE and UM.

Table 7: Research Funder Acknowledged in Highly Cited Papers ( $n=708$ )

\begin{tabular}{l|c||c|c}
\hline \multicolumn{1}{c||}{ Funders } & No of Papers & Percentage & Citations \\
\hline \hline Single funder & 187 & 26.4 & 16787 \\
\hline \hline More than one funder & 248 & 35.0 & 21044 \\
\hline \hline No funding information & 273 & 38.6 & 32829 \\
\hline \hline National funder only & $\mathbf{7 0 8}$ & $\mathbf{1 0 0}$ & $\mathbf{7 0 6 6 0}$ \\
\hline \hline International funder only & 270 & 62.1 & 20753 \\
\hline \hline Collaborative funding & 117 & 26.9 & 13286 \\
\hline \hline Total & 48 & 11.0 & 3792 \\
\hline \hline
\end{tabular}

* Collaborative funding includes international and local funders

\section{f) Malaysian highly cited papers are typically authored by many}

Previous studies have shown that highly cited papers are characterized by an extensive element of co-authorship and co-authored papers serve as a measure of collaborative efforts (Fu et al. 2011; Aksnes 2003; Pislyakov and Shukshina 2014). Malaysian 708 highly cited papers are authored by 7638 authors, indicating an average of 10.8 authors per paper, of which 15.8 percent (1204) are Malaysian-based authors and 83.7 percent (6434) are international authors.

Table 8: Authorship Pattern for Malaysian Highly Cited Papers

\begin{tabular}{l||r||r||r}
\hline \hline \multicolumn{1}{c||}{ Authorship Pattern } & $\begin{array}{c}\text { No of Papers } \\
\text { (Percent) }\end{array}$ & $\begin{array}{c}\text { Malaysian as Reprint } \\
\text { Authors (Percent) }\end{array}$ & $\begin{array}{r}\text { Malaysian as First } \\
\text { Authors (Percent) }\end{array}$ \\
\hline \hline Single author & $17(2.4)$ & $17(3.9)$ & $17(3.8)$ \\
\hline \hline Two author & $88(12.4)$ & $80(18.2)$ & $79(17.5)$ \\
\hline \hline Three author & $132(18.6)$ & $114(25.9)$ & $113(25.0)$ \\
\hline \hline Four author & $116(16.4)$ & $98(22.3)$ & $104(23.0)$ \\
\hline \hline Five author & $75(10.6)$ & $53(12.0)$ & $56(12.4)$ \\
\hline \hline Six author & $47(6.6)$ & $33(7.5)$ & $35(7.7)$ \\
\hline \hline Seven author & $36(5.1)$ & $27(6.1)$ & $26(5.8)$ \\
\hline \hline Eight author & $12(1.7)$ & $6(1.4)$ & $6(1.3)$ \\
\hline \hline Nine author & $10(1.4)$ & $7(1.6)$ & $8(1.8)$ \\
\hline \hline Ten author & $9(1.3)$ & $4(0.9)$ & $5(1.1)$ \\
\hline \hline Multiple authorship* & $121(17.1)$ & $1(0.2)$ & $3(0.7)$ \\
\hline \hline Mega authorship** & $45(6.4)$ & $0(0.0)$ & $0(0.0)$ \\
\hline \hline Total & $\mathbf{7 0 8 ( 1 0 0 . 0 )}$ & $\mathbf{4 4 0 ( 1 0 0 . 0 )}$ & $\mathbf{4 5 2 ( 1 0 0 . 0 )}$ \\
\hline \hline
\end{tabular}

* 11 to 999 authors

** more than 1000 authors 
We observe that Malaysian highly cited papers are typically a result of co-authored work (691, 97.6 percent), and only 17 papers (2.4 percent) are single-authored. Three-authored papers were the dominant authorship pattern $(132,18.6$ percent), followed by more than ten-authored paper $(121,17.1$ percent) and four-authored paper $(116,16.4$ percent). It is interesting to note that mega authorship is evident in 45 papers (6.4 percent), and to be exact, the authorship count of all 45 papers is more than 2000-authored paper, largely from the sciences discipline. Table 5 presents these findings. This clearly indicates that papers with many authors will benefit from a particular mechanism that may increase the citation count. Aksnes (2003) contributes it to potential self-citers and enhanced dissemination through personal communication. However, this might not be so in the context of Malaysian highly cited papers as our earlier findings show low self-citations.

\section{g) Malaysian highly cited papers have a good number of Malaysian as reprint authors and first authors}

Our finding on the collaborative and multi-authored characteristic of Malaysian highly cited papers raised the following sub-research questions: Do Malaysian authors play a major contribution role in Malaysian highly cited paper? The increasing tendency across scientific disciplines to write multi-authored papers makes the sequence of contributors' names important in terms of reflecting the actual contribution and in a posteriori research assessments (Tscharntke et al. 2007). In multi-authored papers, the first author is clearly assigned to the individual making the most contribution to the paper (Bales et al. 2014; Sahu and Panda 2014). The reprint (or corresponding author) in practice, takes the ownership for compliance, pre and post-publication with all journal policies and would be the final decision maker on behalf of all authors for any actions that need to be taken. In the context of Malaysian scholarly publishing, reprint author is now used to indicate seniority and leadership of the research work, and it has been used as an indicator in research assessment. Malaysian highly cited papers have a good number of Malaysian (or Malaysian-based) authors as the first author (452, 63.8 percent) and reprint author (440, 62.1 percent) (Table 8). As Malaysian (or Malaysian based) authors were either first or reprint authors to at least 60 percent of the highly cited papers, it is safe to conclude that Malaysian authors, to a large extent, are major contributors to highly cited papers.

\section{h) Malaysian highly cited papers are mainly affiliated to Malaysian research universities}

At the institutional level, the highly cited papers are affiliated to a total of 1492 institutions, with 7.2 percent (108) Malaysian institutions, and 92.8 percent (1384) international-based institutions. This clearly verifies findings from other studies (Fu et al. 2011; Miyairi and Chang 2012; Persson 2010; Pislyakov and Shukshina 2014) that highly cited papers are characterized by an extensive element of international co-authorship. Generally, we find that Malaysian highly cited papers affiliated to Malaysian institutions are from research universities (68.5 percent), followed by research institutes (11.7 percent), private universities (10.9 percent) and other public universities ( 9.0 percent) (Table 6). The number of citations garnered by research universities is much higher compared to other Malaysianaffiliated institutions. From the total of 708 highly cited papers, about 45.7 percent (268) were affiliated to University of Malaya, followed by 19.9 percent (117) to Universiti Sains Malaysia and 12.6 percent (74) to Universiti Putra Malaysia. The collaboration is mainly with research institutes. 
Table 9: Malaysian Affiliated Institutions and Citation

\begin{tabular}{l||r||r|r}
\hline \hline Institution & No of Papers & Percent & No of Citation \\
\hline \hline Research Universities & 587 & 68.5 & 54558 \\
\hline \hline Research Institutes & 100 & 11.7 & 14662 \\
\hline \hline Private Universities & 93 & 10.9 & 7196 \\
\hline \hline Other Public Universities & 77 & 9.0 & 7960 \\
\hline \hline
\end{tabular}

\section{i) Malaysian highly cited papers are more internationally collaborative}

Our finding on the international co-authorship characteristic of Malaysian highly cited paper raised the following sub-research questions: How do Malaysian highly cited papers characterize in terms of international collaborations? To what extent do Malaysian authors dominate or are dominated in such a collaborative work? What are the key partner countries and their influence on the possibility of a Malaysian paper becoming highly cited? Our analysis shows that the proportion of internationally collaborative papers (co-authored by two or more countries) is 60.6 percent (429). Whereas, the proportion of national interinstitutionally collaborative papers is 6.5 percent (46). A total of 233 papers (32.9 percent) are non-collaborative works.

When a high percentage of the paper involves international collaboration, the notion of Malaysian highly cited papers may become rather problematic. The problem arises in the form of academic authorship responsibility. Aksnes (2003) who studied Norwegian highly cited papers pointed out that "delimitation by countries may be difficult to justify unless corrections are being made for international co-authorship" (p.162). Therefore, to further analyse this, we confine our analysis to those highly cited papers of which Malaysia authors play a major contribution, either as first or reprint authors. We found 66.3 percent (470) of the papers were dominated by Malaysian authors identified as either the first or reprint author. Of this, 40.0 percent (188) are papers with international collaborations and 60.0 percent (282) are national inter-institutional collaborations. Table 10 shows the international collaboration of highly cited papers, with 72.3 percent (136) as result results from a single country collaboration. The largest number of collaborative countries in a single paper is eight.

Table 10: International Collaboration in Malaysian Highly Cited Papers of which Malaysian Authors are First or Single Authors

\begin{tabular}{c||r||r|r}
\hline $\begin{array}{c}\text { No of Collaborative } \\
\text { Countries }\end{array}$ & No of Papers & Percentage & Citation \\
\hline \hline One & 136 & 72.3 & 9920 \\
\hline \hline Two & 30 & 16.0 & 2601 \\
\hline \hline Three & 16 & 8.5 & 974 \\
\hline \hline Four & 5 & 2.7 & 416 \\
\hline \hline Eight & 1 & 0.5 & 33 \\
\hline Total & $\mathbf{1 8 8}$ & $\mathbf{1 0 0 . 0}$ & $\mathbf{1 3 9 4 4}$ \\
\hline \hline
\end{tabular}


There are 47 collaborative countries reported from the 188 papers. Table 11 shows the top 20 key country partners that may influence a Malaysian paper to be highly cited. The highest collaboration is with Iran (10.7 percent, 29), followed by Australia (9.2 percent, 25), and UK (7.4 percent, 20). Finding also indicate that Asian countries (Iran, India, Indonesia, Saudi Arabia, Pakistan, Japan, Singapore, South Korea, Turkey, Egypt, Iraq and Bangladesh) as the most collaborative, with an overall total of 146 (53.7 percent) papers. This indicates that Malaysian authors have the tendency to collaborate with their Asian counterparts unlike studies by Fu et al. (2011) and Miyairi and Chang (2012) that reported internationally collaborative highly cited papers from China, Taiwan and Russia were mostly from collaboration with major industrialized countries. It is interesting to note that Malaysia has only two highly cited collaborative papers with China, and one each with Russia and France.

Table 11: International Collaborative Countries

\begin{tabular}{|c|c|c|c|}
\hline No & $\begin{array}{c}\text { International } \\
\text { Collaborative Countries }\end{array}$ & $\begin{array}{r}\text { No of Paper } \\
\text { (Percentage) }\end{array}$ & Citation \\
\hline 1 & Iran & $29(10.7)$ & 1578 \\
\hline 2 & Australia & $25(9.2)$ & 2777 \\
\hline 3 & UK & $20(7.4)$ & 1943 \\
\hline 4 & India & $19(7.0)$ & 858 \\
\hline 5 & Indonesia & $18(6.6)$ & 1650 \\
\hline 6 & USA & $17(6.3)$ & 1267 \\
\hline 7 & Saudi Arabia & $15(5.5)$ & 729 \\
\hline 8 & Pakistan & $14(5.1)$ & 836 \\
\hline 9 & Japan & $10(3.7)$ & 623 \\
\hline 10 & Canada & $9(3.3)$ & 1033 \\
\hline 11 & Singapore & $9(3.3)$ & 362 \\
\hline 12 & South Korea & $9(3.3)$ & 809 \\
\hline 13 & Turkey & $7(2.6)$ & 279 \\
\hline 14 & Egypt & $6(2.2)$ & 648 \\
\hline 15 & Iraq & $6(2.2)$ & 143 \\
\hline 16 & Netherlands & $5(1.8)$ & 125 \\
\hline 17 & Nigeria & $4(1.5)$ & 125 \\
\hline 18 & Bangladesh & $4(1.5)$ & 120 \\
\hline 19 & Sweden & $4(1.5)$ & 403 \\
\hline 20 & Germany & $3(1.1)$ & 810 \\
\hline
\end{tabular}

\section{CONCLUSION}

This study has systematically identified and characterized Malaysian highly cited papers. The findings reveal the following nine characteristics of Malaysian highly cited papers: (a) represented highly by articles, but reviews have more impact; (b) lowly self-cited; (c) mainly published in the first quartile; (d) from the sciences; (e) outcomes of national funded research; ( $f$ ) typically authored by many; $(g)$ largely Malaysian as reprint authors and first authors; (h) mainly affiliated to Malaysian research universities; and (i) more internationally 
collaborative. This paper has shown that these are characteristics of highly cited papers, but to what extent can these characteristics be used as indicators need further investigation. These characteristics are in line with other studies of highly cited papers (Aksnes 2003; Chen, Arsenault and Larivière 2015; Fu et al. 2011; Miyairi and Chang 2012; Persson 2010; Pislyakov and Shukshina 2014; Tijssen et al. 2002). In addition, our study highlights new findings that highly cited papers are more represented by articles rather than reviews papers, affiliated to research-intensive universities and outcomes of national funded research. Moreover, home-grown researchers dominated as either first or reprint authors in internationally collaborative Malaysian highly cited papers.

We were exposed to some limitations in this paper. As a small scientific nation, Malaysia has a rather limited production of papers being highly cited, and we identified nine characteristics of highly cited papers based on a small pool of dataset. The characteristics may change if the sample of the highly cited papers changed continuously. However, it is notable that the 708 papers represent the highest cited in their respective subject fields in Malaysia from 2006 to 2016. It is concluded that it is important to identify the highly cited and to characterize the overall citation landscape for Malaysia. The results of our study provide various benefits for researchers and practitioners in Malaysia. The results may help early career researchers to strategize their publication practices to collaborate with international researchers for quality dynamics, and publish in high impact journals for visibility dynamics. Using Malaysia's highly cited papers will encourage reinforcing the list of 'characteristics' of highly cited papers found in various literatures from other studies. In the context of Malaysia or national citation indicators, an analysis of the underlying data from this finding for national indicators may be useful in creating awareness towards the existence of articles with great influence on what is characteristically considered an indicator of national performance especially for Malaysian Research Assessment (MyRA)tools. It is hoped that this paper will encourage further discussions among the scientific and national citation indicators community towards further analysis and formal characterization of highly cited papers.

\section{ACKNOWLEDGEMENT}

This research received no specific grant from any funding agency in the public, commercial, or not-for profit sectors.

\section{REFERENCES}

Abrizah, A. and Wee, M. C. 2011. Malaysia's computer science research productivity based on publications in the Web of Science, 2000-2010. Malaysian Journal of Library \& Information Science, Vol. 16, no. 1: 109-124.

Abrizah, A., Zainab, A. N., Edzan, N. N. and Koh, A. P. 2013. Citation Performance of Malaysian Scholarly Journals in the Web of Science, 2006-2010. Serials Review, Vol. 39, no. 1: 47-55.

Aksnes, D. W. 2003. Characteristics of highly cited papers. Research Evaluation. Vol. 12, no. 3: 159-170. http://doi.org/10.3152/147154403781776645.

Aksnes, D. W. and Sivertsen, G. 2004. The effect of highly cited papers on national citation indicators. Scientometrics, Vol. 59, no. 2: 214-224.

Alatas, S. F. 2000. Academic dependency in the social sciences: Reflections on India and Malaysia. American Studies International, Vol. 38, no. 2: 80. 
Ale Ebrahim, N., Ebrahimian, H., Mousavi, M. and Tahriri, F. 2015. Does a long reference list guarantee more citations? Analysis of Malaysian highly cited and review papers. The International Journal of Management Science and Business, Vol. 1 no. 3: 6-15. Available at: http://doi.org/10.6084/m9.figshare.1321205.

Bakri, A. and Willett, P. 2011. Computer science research in Malaysia: A bibliometric analysis. Aslib Proceedings, Vol. 63, no. 2-3: 321-335. Available at: http://doi.org/10.1108/00012531111135727.

Bales, M. E., Dine, D. C., Merrill, J. A., Johnson, S. B., Bakken, S., and Weng, C. 2014. Associating co-authorship patterns with publications in high-impact journals. Journal of Biomedical Informatics, Vol. 52: 311-318.

Baltussen, A., and Kindler, C. H. 2004. Citation classics in critical care medicine. Intensive Care Medicine, Vol. 30, no. 5: 902-910. Available at: http://doi.org/10.1007/s00134-0042195-7.

Bornmann, L., Stefaner, M., Anegón, F. D. M., and Mutz, R. 2013. Ranking and mapping of universities and research-focused institutions worldwide based on highly-cited papers : A visualization of results from multi-level models. Online Information Review, Vol. 38, no. 1: 43-58.

Chen, S., Arsenault, C. and Larivière, V. 2015. Are top-cited papers more interdisciplinary? Journal of Informetrics, Vol. 9, no. 4: 1034-1046. Available at: http://doi.org/10.1016/j.joi.2015.09.003

Dance, A. 2012. Authorship: Who's on first? Nature, Vol. 489, no. 7417: 591-593. Available at: http://doi.org/10.1038/nj7417-591a.

Davarpanah, M. R. 2009. The international publication productivity of Malaysia in Social Sciences. Journal of Scholarly Publishing, Vol. 41, no.1: 67-91. Available at: http://doi.org/10.3138/jsp.41.1.67.

Davarpanah, M. R. and Farzaneh, A. 2009. Author self-citation pattern in science. Library Review, Vol. 58, no. 4: 301-309.

Ductor, L. 2015. Does co-authorship lead to higher academic productivity? Oxford Bulletin of Economics and Statistics, Vol. 77, no. 3: 385-407.

Fu, H. Z., Chuang, K. Y., Wang, M. H. and Ho, Y. S. 2011. Characteristics of research in China assessed with Essential Science Indicators. Scientometrics, Vol. 88, no. 3: 841-862. Available at: http://doi.org/10.1007/s11192-011-0416-8

Garfield, E. 1955. Citation Indexes for Science: A new dimension in documentation through association of ideas. Science, Vol. 122, no. 3159: 108 LP-111. Available at: http://science.sciencemag.org/content/122/3159/108.abstract.

Garfield, E. 1990. How ISI selects journals for coverage: Quantitative and qualitative considerations. Essays of an Information Scientist, Vol. 13: 185-193. Available at: http://doi.org/10.1007/s13398-014-0173-7.2

Garousi, V. and Fernandes, J. M. 2016. Highly-cited papers in software engineering: The top100. Information and Software Technology, Vol. 71: 108-128. Available at: http://doi.org/10.1016/j.infsof.2015.11.003.

Glänzel, W. and Schubert, A. 1995. Predictive aspects of a stochastic model for citation processes. Information Processing and Management, Vol. 31, no. 1: 69-80. Available at: http://doi.org/10.1016/0306-4573(95)80007-G.

Fang, Hui. 2015. A theoretical model of scientific impact based on citations. Malaysian Journal of Library \& Information Science, Vol. 20, no.3, 2015: 1-13.

King, C. 2016. Honoring Malaysia's Rising Stars. Clarivate Analytics. Available at: http://stateofinnovation.com/honoring-malaysia\%E2\%80\%99s-rising-stars.

Kumar, S. and Jan, J. M. 2013. Mapping research collaborations in the business and management field in Malaysia, 1980-2010. Scientometrics, Vol. 97, no. 3: 491-517. 
Available at: http://doi.org/10.1007/s11192-013-0994-8.

Leydesdorff, L. and Bornmann, L. 2011. How fractional counting of citations affects the impact factor: Normalization in terms of differences in citation potentials among fields of science. Journal of the American Society for Information Science and Technology, Vol. 62, no. 2: 217-229. Available at: http://doi.org/10.1002/asi.21450.

Martín-Martín, A., Orduna-Malea, E., Ayllón, J. M., Delgado López-Cózar, E. and López-Cózar, E. D. 2016. A two-sided academic landscape: portrait of highly-cited documents in Google Scholar (1950-2013). Revista Española de Documentación Científica, Vol. 39, no. 4: 149. Available at: http://doi.org/10.3989/redc.2016.4.1405.

Meho, L. I., and Yang, K. 2007. Impact of data sources on citation counts and rankings of LIS faculty: Web of Science versus Scopus and Google Scholar. Journal of the American Society for Information Science and Technology, Vol. 58, no. 13: 2105-2125.

Miyairi, N., and Chang, H. W. 2012. Bibliometric characteristics of highly cited papers from Taiwan, 2000-2009. Scientometrics, Vol. 92, no. 1: 197-205. Available at: http://doi.org/10.1007/s11192-012-0722-9.

Moed, H. F. 2010. Measuring contextual citation impact of scientific journals. Journal of Informetrics, Vol. 4, no. 3: 265-277. Available at: http://doi.org/10.1016/j.joi.2010.01.002.

Paladugu, R., Schein, M., Gardezi, S. and Wise, L. 2002. One hundred citation classics in general surgical journals. World Journal of Surgery, Vol. 26, no. 9: 1099-1105. Available at: http://doi.org/10.1007/s00268-002-6376-7.

Patsopoulos, N. A. 2006. Origin and funding of the most frequently cited papers in medicine: database analysis. British Medical Journal, Vol. 332, no. 7549: 1061-1064.

Paul-Hus, A., Desrochers, N. and Costas, R. 2016. Characterization, description, and considerations for the use of funding acknowledgement data in Web of Science. Scientometrics, Vol. 108, no. 1: 167-182.

Persson, O. 2010. Are highly cited papers more international? Scientometrics, Vol 83, no. 2: 397-401. Available at: http://doi.org/10.1007/s11192-009-0007-0.

Pislyakov, V. and Shukshina, E. 2014. Measuring excellence in Russia: Highly cited papers, leading institutions, patterns of national and international collaboration. Journal of the Association for Information Science and Technology, Vol. 65, no. 11: 2321-2330. Available at: http://doi.org/10.1002/asi.23093.

Ponce, F. A., and Lozano, A. M. 2010. Highly cited works in neurosurgery. Part I: The 100 topcited papers in neurosurgical journals. Journal of Neurosurgery, Vol. 112, no. 2: 223232. Available at: http://doi.org/10.3171/2009.12.JNS091599.

Sahu, S. R. and Panda, K. C. 2014. Does the multi-authorship trend influence the quality of an article? Scientometrics, Vol. 98, no. 3: 2161-2168.

Sanni, S. A., Safahieh, H., Zainab, A. N., Abrizah, A. and Raj, R. G. 2013. Evaluating the growth pattern and relative performance in Nipah Virus research from 1999 to 2010. Malaysian Journal of Library \& Information Science, Vol. 18, no. 2: 14-24.

Shadgan, B., Roig, M., HajGhanbari, B. and Reid, W. D. 2010. Top-Cited articles in rehabilitation. Archives of Physical Medicine and Rehabilitation. Vol. 91, no. 5: 806-815.

Tahira, M., Alias, R. A. and Bakri, A. 2015. Application of $h$ and h-type indices at meso level: A case of Malaysian engineering research. Malaysian Journal of Library \& Information Sciences, Vol. 20, no. 3: 77-86.

Testa, J. 2016. The Thomson Reuters journal selection process. Available at: http://thomsonreuters.com/products_services/science/free/essays/journal_selection process.

Tijssen, R., Van Leeuwen, T. and Visser, S. 2002. Benchmarking international scientific excellence: Are highly cited research papers an appropriate frame of reference? Scientometrics, Vol. 54, no. 3: 381-397. http://doi.org/10.1023/A 
Tscharntke, T., Hochberg, M. E., Rand, T. A., Resh, V. H. and Krauss, J. 2007. Author sequence and credit for contributions in multiauthored publications. PLoS Biology. Vol. 5, no. 1: 18. Available at: http://doi.org/10.1371/journal.pbio.0050018.

Zainal, H. and Zainab, A. N. 2011. Biomedical and health sciences publication productivity from Malaysia. Health Information and Libraries Journal, Vol. 28, no. 3: 216-225. Available at: http://doi.org/10.1111/j.1471-1842.2011.00943.x. 